\title{
Using Post-Task Written Vocabulary Exercises in Task-Based Instruction
}

\author{
Siu-on Lee \\ The Chinese University of Hong Kong, Hong Kong
}

\begin{abstract}
Task-based instruction, which emphasizes authentic communication and holistic language learning opportunities, has been a prominent topic in Asia for both researchers and teachers. Still, relatively few studies have addressed vocabulary acquisition from a task-based perspective, notwithstanding second language learners' need to acquire thousands of words to deal with various language uses. In this paper, the teaching procedure and empirical data will be presented to showcase how 27 Hong Kong learners benefited from a combination of an authentic task and written vocabulary exercises in terms of receptive and productive retention of the target words. The results indicated that such a combination yielded better immediate and delayed retention than a purely communicative approach; however, form recall remained the most difficult type of word knowledge irrespective of the treatments. This highlights the value of traditional elements such as written exercises in task-based instruction.
\end{abstract}

Second language (L2) learners must learn thousands of words to deal successfully with a range of language uses, and for long this has been one of the greatest hurdles facing learners in acquiring English. Even the most gifted learners need no less than one year to acquire 1,000 words, and the time required can be much longer for average learners (Nation \& Chung, 2009). It is not surprising then, that both teachers and learners are eager to know what can foster such acquisition. A strategic plan about how to handle vocabulary is necessary, and programmes overemphasising communication or authenticity may fall short in this regard.

While educational policies in Asia have heavily favoured task-based instruction (also referred to as task-based language teaching, henceforth referred to here as TBI) and other communicative, holistic approaches in the last decade, whether such pedagogical approaches are effective with respect to L2 vocabulary learning is still open to question. As pointed out by Laufer (2005), they cannot always assure learners of a wide and repeated coverage of new words. In contrast, traditional written vocabulary practices are fairly effective in improving both receptive and productive acquisition (Folse, 2004, 2006; Laufer, 2003). Although some advocates of TBI may proscribe exercises, considering them decontextualized and repetitious, it is worth exploring if a combination of TBI and numerous vocabulary practices can enhance the retention of words in terms of quality, quantity, and duration. 


\section{A Quick Note on Task-Based Instruction}

The concept of TBI was developed in the 1980s by second language acquisition (SLA) researchers and teachers who were discontented with teacher-centred, form-oriented language teaching practice. The rationale behind TBI is that key language learning processes take place in holistic rather than analytic language activities, and tasks are invaluable in achieving this (Samuda \& Bygate, 2008). The primary unit for both designing a language programme and individual lessons should be a task because it creates opportunities for communication and noticing form / meaning / function relationships, which are the conditions essential for the development of communicative competence in an L2 (Willis \& Willis, 2007).

Though there are various definitions of a task, most require that a task meet the following criteria (Ellis, 2009): the focus should be mainly on meaning but not language; there should be a gap to be filled such as exchanging information or sharing an opinion; learners should utilize their own linguistic and world knowledge; and the outcome should be non-linguistic, with some real-life relevance.

With regard to research, tasks have been used in a multitude of studies to further explain how SLA occurs, and what variables influence its rate and final outcomes. Researchers have been particularly interested in areas as follows (Van den Branden, Bygate, \& Norris, 2009):

- The impact of specific task types on interactive behaviour and the learning that results from it

- The impact of the performance of tasks on the acquisition of particular items

- The impact of manipulating some features and variables on fluency, accuracy, and complexity

- The impact of incidental, implicit focus on form on language learning

- The relationship between individual differences and performance

As governments in Asia are keen on raising the number of people in their population who can communicate in English, TBI, as well as various versions of communicative language teaching, has been the predominant approach in national policies and syllabuses. Even so, TBI has not always been implemented consistently or willingly. Teachers frequently encounter problems such as classroom management, learners' avoidance of English, conflict with traditional values, incompatibility of TBI with assessment methods, and minimal teacher development efforts (Adams \& Newton, 2009; Littlewood, 2007). How they tackle these problems and adapt TBI in a sensitive and appropriate way has become a new area of interest among TBI researchers.

\section{How Well Can TBI Cater for Vocabulary Learning?}

Learning an L2 involves various aspects of that language, yet for a long time, vocabulary has received less attention in teaching, resulting in frustration among learners. This phenomenon can also be found in TBI classrooms, where learners are expected to utilize their own resources to communicate and solve problems collaboratively.

The question of whether tasks can be used to promote vocabulary development is a relatively unresearched direction (Samuda \& Bygate, 2008). This view is also shared by Swan (2005), who claims that $\mathrm{TBI}$ is characteristically limited to the acquisition of grammar, but not vocabulary or phonology. The limitation of explicit vocabulary instruction in TBI is partly attributable to the belief that natural input, such as reading newspapers and conversation outside the classroom, is the major source of vocabulary acquisition - that learners notice new words, infer meanings from context, and retain them immediately or in additional encounters. 
Unfortunately, as summarized by Laufer (2003), learners sometimes overestimate their understanding of words and leave unfamiliar words unnoticed, and guessing does not work when the context provides no clue at all. Also, one may need to see a word 10 times to retain it (Saragi, Nation, \& Meister, 1978), and a coverage of as high as 98 percent of the running words is needed for reading a wide range of authentic texts (Nation, 2006). Even if we are so optimistic as to expect a 25 percent chance of reappearance for each new word in random texts, a learner has to read 200,000 words just to learn about 100 new words.

Some versions of TBI do acknowledge that an occasional shift to linguistic features and vocabulary may not be adequate (Long \& Robinson, 1998). Thus, there is a need to add certain kinds of vocabulary instruction to complement communicative activities, usually in the form of pre-tasks or post-tasks (Swan, 2005). However, this raises a body of scholastic and ideological issues at the same time. How can a substantial number of pre-selected new words be "hidden" (Ellis, 2009, p. 223) in a task that is claimed to resemble natural, unpredictable use of language? How much help (e.g., definitions, paraphrases, contextualizations, and synonyms) is the teacher allowed to offer without threatening "the integrity of the task" (Ellis, 2003, p. 246)? What should learners do in a post-task so that it is still a communicative task, rather than a non-communicative exercise? For teachers with a vague understanding of TBI, coping with these concerns successfully is taxing, if not unrealistic.

From the perspective of beginner learners, it is hard to shift attention to numerous unknown words in oral interaction, because they know little about the linguistic conventions for opening and closing conversations, interrupting, challenging, and clarifying (Swan, 2005). As an outcome, they may either bypass the unknown words and the communication problems caused by them altogether, or remain silent and rely heavily on teacher assistance (Kim, 2008). Even if they manage to attend to the target words, they are unlikely to do any better than recognizing the most salient meaning (Sonbul \& Schmitt, 2009), and consequently the gap between their productive and receptive word knowledge will be widened further.

In sum, various salient features of TBI such as negotiation for meaning and modified output may promote vocabulary growth as with the acquisition of other skills. However, as concluded by Schmitt (2008), it is expecting too much to assume that a sufficient amount of words will be learnt from exposure to language tasks that are primarily communicationoriented, and more controlled, structured approaches are called for to make learners stay active for longer than just several minutes of engagement within a task.

\section{The Need for Form-Focused Vocabulary Exercises}

To ensure the balanced development of vocabulary, a roughly even amount of time has to be allocated for meaning-focused input, meaning-focused output, fluency development, and language-focused learning (Nation \& Chung, 2009). The pre-task and task cycle can involve learners in the first two strands, and fluency can be enhanced in reports and the planning before them. But a task-based lesson that is entirely composed of group work and oral exchange can rarely provide individuals with adequate language-focused learning. One way to mend this imbalance is to use written vocabulary exercises in the post-task phase.

A decisive factor in vocabulary acquisition is frequency of retrieval, but unlike grammatical structures, words typically appear less often in both input and output. A task-based lesson can easily elicit the frequent use of a certain grammatical structure, such as the progressive aspect, but not 10 or 15 new words. With written exercises at the end of a task-based lesson, multiple retrievals of each target word can be guaranteed. One or two more retrievals can give rise to 
significant gains in aspects such as meaning and syntax recognition (Webb, 2007). Another advantage of using exercises as a post-task is the shorter preparation time needed. New sets of sentences can easily be written to ensure exposure in different contexts, and learners will always end up with correct examples to study, unlike after guessing or negotiation. Lastly, while the task cycle causes learners to focus attention on certain new words they feel urged to use to convey a message, the written exercises help learners by channelling their attentional resources to words that they find harder to grasp during communication.

If task-oriented teaching cannot assure learners of the necessary reoccurrence and retrieval of words, one way to balance authenticity and vocabulary growth is to use word focus practices, where words are the objects of learning, not only tools of communication (Laufer, 2005). Though some may consider these seemingly shallow exercises inconsonant with the rationales behind $\mathrm{TBI}$, it must be recognized that there is no single way of doing TBI, and an integrated syllabus can make use of both TBI and more traditional approaches (Ellis, 2009). Now that TBI is applied across diverse learner populations, it is imperative to examine what available taskbased techniques prove the most effective in L2 vocabulary acquisition in Asia, where the vocabulary sizes of high school and undergraduate students typically fall short of even relatively conservative requirements (Laufer, 2000).

\section{Method}

\section{Participants}

Twenty-seven students (18 female, 9 male) enrolled in an associate degree program at the Hong Kong Community College of the Polytechnic University of Hong Kong took part in this study. They were aged 18 to 20, and all of them had passed at least five subjects in the Hong Kong Certificate of Education Examination, including Chinese and English. It was assumed that they all had at least intermediate mastery of English.

\section{Instruments}

The main instruments used in the study were three paper-and-pencil tests - a form-recall test, a meaning-recall test, and a meaning-recognition test. The first test was a completion test to assess form recall. Several letters of each target word and a concise meaning were provided as below:

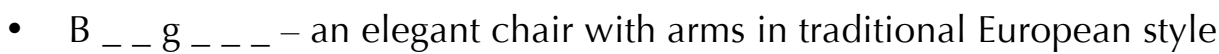

The next test was to assess meaning recall, and either L1 translations or L2 definitions were accepted.

- $\quad$ Easel -

Lastly, multiple-choice items were used to measure meaning recognition. There were five choices for each item: the correct answer, three distractors, and an "I don't know" option to reduce guessing.

- Armoire
$\square$ A. a decorated bottle
$\square$ B. a beautiful wardrobe with doors
$\square$ C. a sofa usable as a bed
$\square$ D. a stand for holding a blackboard
$\square$ E. I don't know 
The two recall tests were done before the recognition test so as to avoid a test effect. Apart from that, as Laufer, Elder, Hill, and Congdon (2004) found tests of form recognition and meaning recognition tended to yield similar scores, this study only tested meaning recognition.

\section{Target Words}

This study used the 10 words below in all treatments, exercises, and tests:

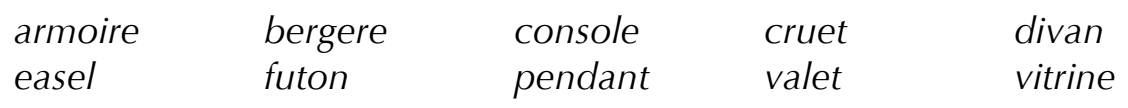

A major concern in selecting the target words was that they be of similar difficulty to the participants. Therefore, only nouns were chosen to reduce to a role of the part of speech as an extraneous variable; only single words, not phrases, were included; words that have a morphological clue to the meaning (e.g., lounger, glider, and recliner) were rejected; and only words with two syllables and of similar length were chosen. Next, to evaluate the likelihood of target word familiarity among the participants, the researcher adopted a procedure from Laufer's study (2003). A group of postgraduate students at the Chinese University of Hong Kong who were highly proficient in English was first given the 10 words to translate or explain. The mean knowledge was lower than one out of 10 . Since the study participants had lower language proficiency than the postgraduate students, it was assumed that they had no prior knowledge of these words. Furniture and household items were chosen to be the theme of all treatments owing to their low relevance to the participants' compulsory English courses. This minimized the potential benefit to the participants, as well as the potential risk to the students who decided not to participate.

\section{Procedure}

The 27 participants were assigned randomly to one of two one-hour treatment groups: the Task-Plus-Discussion Group and the Task-Plus-Exercise Group. After the treatments, a 30minute post-test was immediately administered. One week later, the same test (item order changed) was administered unannounced to assess the retention of the target words over time.

The task-plus-discussion group. At the pre-task stage, the participants were invited to talk about the furniture in their homes, and the instructor wrote the words provided by the participants on the board. After that, 10 photos showing the target items were distributed to the participants, and they asked each other to name the items and describe their uses. To introduce these target words, the instructor showed the corresponding pictures on the screen, read the words aloud, and explained them one by one. This stage took approximately 15 minutes. This photo-sharing part was of great importance because it channelled the participants' attention to several target words. While many words were not known by individuals, most words were known by at least one participant. Even without outside help, as long as the participants were prepared to negotiate for meaning, they had sufficient resources to tackle most unknown words at later stages (Newton, 2001).

In the task cycle, the participants formed groups of four or five. Each group was given an apartment layout and a list of the 10 target words (but not their corresponding pictures). The participants discussed where to put the 10 items and why. To enhance authenticity, the existing furniture in the apartment could also be moved. The participants were strongly encouraged to speak in English only, negotiate for meaning of unknown words, and refrain from using a dictionary. They were also reminded to rehearse for a compulsory oral report in which every member would describe and justify the arrangement of one or two furniture items. 
The discussion and rehearsal took about 15 minutes, and another 15 minutes were allocated for the group reports.

When all group reports were finished, the participants were offered a chance to freely produce the target words during the remaining 15 minutes. They discussed in groups what furniture items they wanted for their homes. The importance of using the new words was stressed, but no teacher-initiated focus on form was given. They were not required to report their decisions or reasons to other groups either.

The task-plus-exercise group. This treatment group went through the same pre-task and task cycle, but instead of adopting a completely communicative approach, this group used written vocabulary exercises as a post-task in the last 15 minutes. The formats of the exercises were the same as that of the instruments: form recall, meaning recall, and meaning recognition. As 15 minutes was less than enough time to finish all the exercises, the participants were given the liberty to select which parts or items to do. Answers were provided at the end of this treatment.

A summary of the two treatments is shown in Table 1 below:

\section{Table 1}

\section{Group Sequences and Treatments}

\begin{tabular}{cc}
\hline Task-Plus-Discussion & Task-Plus-Exercise \\
\hline \multicolumn{2}{c}{$\begin{array}{c}\text { Pre-task (15 min) } \\
\text { Word and photo sharing } \\
\text { Introduction of target words }\end{array}$} \\
\multicolumn{3}{c}{$\begin{array}{c}\text { Task cycle (30 min) } \\
\text { Furniture task } \\
\text { Rehearsal and oral report }\end{array}$} \\
\hline $\begin{array}{c}\text { Post-task (15 min) } \\
\text { Free discussion }\end{array}$ & Post-task (15 min) \\
Immediate post-test (30 min) \\
One-week delayed post-test (30 min)
\end{tabular}

\section{Data Scoring}

All tests were scored by the researcher and two student assistants. For the recall tests, a correct response would receive a full point. Any unattempted item or wrong response would receive a score of zero. When spelling mistakes were found, however, the researcher and the assistants negotiated the degree to which the responses were correct or not. For example, a remote approximation of the target word (e.g., curet for cruet) or an incomplete definition would receive half a point. This measure was needed to take partial learning and knowledge into account. As regards the multiple-choice recognition test, a correct answer would be awarded a full point, "I don't know" or no answer would score zero, and any distractor selected would be scored -0.33 to adjust scores for guessing.

\section{Results}

Table 2 below represents the development of each type of vocabulary knowledge in the two treatments, both immediately and after a week. The maximum score for all the tests was 10 . 


\section{Table 2}

Immediate and Delayed Vocabulary Gains after Different Treatments

Type of Vocabulary Knowledge

\begin{tabular}{|c|c|c|c|c|c|c|c|}
\hline \multirow[b]{2}{*}{ Test Time } & \multirow[b]{2}{*}{ Treatment } & \multicolumn{2}{|c|}{ Form Recall } & \multicolumn{2}{|c|}{ Meaning Recall } & \multicolumn{2}{|c|}{ Meaning Recognition } \\
\hline & & Mean & SD & Mean & SD & Mean & SD \\
\hline \multirow[t]{2}{*}{ Immediate } & Task-Plus-Discussion & 4.04 & 1.46 & 5.07 & 1.38 & 6.45 & 1.36 \\
\hline & Task-Plus-Exercise & 5.42 & 1.02 & 6.38 & 1.12 & 7.69 & 1.18 \\
\hline \multirow[t]{2}{*}{ Delayed } & Task-Plus-Discussion & 2.71 & 1.40 & 4.71 & 1.14 & 5.98 & 1.24 \\
\hline & Task-Plus-Exercise & 4.23 & 1.30 & 5.92 & 0.95 & 7.00 & 1.16 \\
\hline
\end{tabular}

The data collected were also analyzed using a repeated measures analysis of variance (ANOVA). The alpha level for all analyses was .05. The effect for test time was found to be significant, $F(1,25)=55.25, p<.0005$. Type of vocabulary knowledge was even more significant, $F(2,50)=115.35, p<.0005$, so certain types of vocabulary knowledge were indeed harder to grasp for the participants. Treatment, which was the focus of the present study, also appeared to have a significant effect, although it was not as salient as the previous two variables, $F(1,25)=9.96, p=.004$. At the same time, some interaction was found between time and type of vocabulary knowledge, $F(2,50)=11.67, p<.0005$. This reflects that not all types of vocabulary knowledge declined at the same rate. However, very little interaction was found between time and treatment, as well as between type of vocabulary knowledge and treatment. Thus, using exercises as a post-task did not seem to slow down the decline of vocabulary knowledge in general, and the relative difficulty of the three types of vocabulary knowledge was almost the same for both treatment groups.

\section{Discussion}

On the basis of these findings, some possible answers to the research inquiries emerge.

Generally, TBI has the potential to bring about moderate to large vocabulary gains at the three levels of form-meaning mastery. It is not unlikely that the characteristics of tasks - authentic materials, learner-centred communication, negotiation for meaning, integration of new and existing knowledge, and a meaningful, non-linguistic outcome - can foster vocabulary acquisition in the same manner they foster the acquisition of other language features. Another factor that may have an effect is wider acoustic variability in a task-based classroom. As suggested by Barcroft and Sommers (2005, p. 410), the use of acoustically varied presentation formats can help learners form "more associative hooks and more robust representations" of the words taught. To make that happen, communicative tasks and group reports as multi-talker presentation formats can be used to promote L2 vocabulary learning.

Another main concern in this paper is the quality of learners' initial stage of vocabulary learning in task-based classes. The two treatments in the present study appeared to facilitate vocabulary learning in similar ways: meaning recognition was learnt best, followed by meaning recall. The gain in form recall was the smallest. Likewise, although the learners' performance dropped in all delayed tests, form recall exhibited the most marked fall. These results followed the general pattern that productive knowledge (recall) is harder to acquire than receptive knowledge (recognition). One possibility is that the participants prioritized meaning 
rather than word form, which was natural given that both treatments in this study were communication-oriented. In fact, it is not uncommon that teachers focus primarily on meaning when teaching new words, regardless of the teaching approach adopted (Sonbul \& Schmitt, 2009). This study once again stresses the importance of word form, as more than often it is the most difficult aspect to learn.

Many educators view written vocabulary exercises as obsolete or superficial in comparison with sentence or essay writing. In this study, however, the participants who did exercises as a post-task clearly outperformed those whose post-task was a discussion. In addition, scores from the Task-Plus-Exercise Group were more tightly clustered around the means. Such a phenomenon might be an indication that even learners who did not participate much in the task cycle managed to pick up a considerable amount of word knowledge in the post-task exercises. This has a profound implication for vocabulary learning in a communicative, cooperative task, because learners are unlikely to have adequate time or opportunities to use all target words in their output, unless they try to dominate the task. What is more, even if they pay close attention to the speech of the other members, the word form and the meaning (or at least some clues to it) are often presented at the same time. This only results in repetition, which is less helpful than retrieval (Folse, 2004). Therefore, if a post-task comprising written exercises can not only elicit additional retrievals of partially-learnt words, but also channel learners' attention to words that they have overlooked or avoided, it will be of enormous value to learners and teachers alike.

Lastly, both groups retained less word knowledge at all levels in the delayed post-tests, and the drops exhibited by both groups were comparable. One possible interpretation is that the additional word repetitions and retrievals that occurred in the post-task exercises were not robust enough to transfer all target words from short-term memory to long-term memory. Although there is no definite answer to how many encounters are needed for words to be retained permanently, 10 may be a reasonable estimation (Saragi, Nation, \& Meister, 1978). Whether a one-hour task-based lesson can achieve this is open to debate. After all, in a taskbased syllabus, new words that are thematically unrelated to the ever-changing content may not appear again. Thus, repeated encounters can only be ensured through activities not closely related to the current task (Laufer, 2005). This necessitates the use of less fashionable written exercises, but how long and how often they should be used is within the teacher's discretion.

\section{Conclusion}

The main pedagogical implication of this study is based on the superiority of a communicative task plus written exercises over a task alone. Although results show that the use of communicative tasks can indeed promote vocabulary learning at various levels, a written exercise component that lasts no longer than 15 minutes can raise the gain significantly. Such exercises are easy to develop, completion time is less than that with sentence or essay writing, and either the teacher or the learners themselves can do the correction quickly (Folse, 2006). Another advantage that should not be overlooked is that written vocabulary exercises can take the form of computer applications and traditional paperwork. Therefore, the use of vocabulary exercises as a post-task is highly feasible in classrooms with limited facilities, as well as in institutes that can afford advanced technology.

There are certainly limitations in this study that should be underscored. To begin with, the number of participants needed to be higher and the generalization of the results for this study is very limited. Next, owing to a tight teaching schedule, the researcher gave the participants 
only a one-hour treatment, and all the testing instruments were in written form, notwithstanding that the problem-solving task, the group report, and the discussion post-task were done orally. Also, the participants' exercises were not collected or analyzed, so how learners make use of the written vocabulary exercises within a limited time is unknown. Do they prefer to work on well-learnt or unfamiliar words? Do learners who are more active in communicative tasks complete more items? Qualitative measures such as observation and interviews are required to look into these questions without exerting extra pressure on the learners.

It should be noted that the present study investigated only the acquisition of the basic meaning of a word, so other aspects of vocabulary learning (such as associations and collocation) remain untouched. How well these aspects can be learnt in a similar setting merits further investigation. Similarly, as only nouns were learnt and tested, further studies are needed to empirically explore if the results are generalizable to other word classes. Future research could also add learner differences as an independent variable. Although TBI in its purest form would seem to favour holistic learners (Willis, 1996), an exercise component in TBI might be more helpful to analytic or beginner learners.

While the suggestions above are valuable to researchers, teachers may be more concerned about what kinds of exercises are the best for learners. Although this study limited itself to three kinds of exercises, there are actually numerous permutations of vocabulary practices. A brief sample of some exercise possibilities can be found in the appendix. It should be stressed, however, that how often learners retrieve a word is more important than what they do with it. Various types of exercises should be used not because some are inherently better, but because this guarantees a more balanced exposure and helps to retain learners' attention. Even when class time is so short that no written exercises can be given, teachers might consider orally asking questions at various cognitive levels about newly taught words (Folse, 2004). For example, after the task cycle used in this study, the teacher could ask the whole class:

- Which words are related to a bed? (divan, futon, etc.)

- In what ways is a bergere different from your chair? (with arms, more expensive, etc.)

- What is a console normally made of? (wood, plastic, etc.)

Such questions require very little teacher preparation, yet they force learners to retrieve the words multiple times from different perspectives. Moreover, every additional activity, however short it is, signals the teacher's expectation that a certain amount of vocabulary should be learnt in each week or in each unit; it is hoped that learners will respond to such an expectation.

\section{Author Note}

Siu-on Lee, Department of English, the Chinese University of Hong Kong, Hong Kong

I would like to thank the students of the Hong Kong Community College of the Polytechnic University of Hong Kong for participating in this study, and the Chinese University of Hong Kong for the financial help provided to present this study in the 7th Annual CamTESOL Conference on English Language Teaching in Phnom Penh, Cambodia.

Correspondence concerning this article should be addressed to Siu-on Lee, Department of English, 3/F Fung King Hey Building, the Chinese University of Hong Kong, Shatin, NT, Hong Kong. Email: soltim.elt@gmail.com 


\section{References}

Adams, R., \& Newton, J. (2009). TBLT in Asia: Constraints and opportunities. Asian Journal of English Language Teaching, 19, 1-17.

Barcroft, J., \& Sommers, M. S. (2005). Effects of acoustic variability on second language vocabulary learning. Studies in Second Language Acquisition, 27, 387-414. http://dx.doi.org/10.1017/S0272263105050175

Ellis, R. (2003). Task-based language learning and teaching. Oxford, England: Oxford University Press.

Ellis, R. (2009). Task-based language teaching: Sorting out the misunderstandings. International Journal of Applied Linguistics, 19(3), 221-246. http://dx.doi.org/10.1111/j.14734192.2009.00231.x

Folse, K. (2004). Vocabulary myths: Applying second language research to classroom teaching. Ann Arbor, MI: University of Michigan Press.

Folse, K. (2006). The effect of type of written exercise on L2 vocabulary retention. TESOL Quarterly, 40(2), 273-293.

Kim, Y. (2008). The contribution of collaborative and individual tasks to the acquisition of L2 vocabulary. The Modern Language Journal, 92(1), 114-130.

http://dx.doi.org/10.1111/j.1540-4781.2008.00690.x

Laufer, B. (2000). Task effect on instructed vocabulary learning: The hypothesis of 'involvement.' Selected Papers from AILA '99 Tokyo (pp. 47-62). Tokyo, Japan: Waseda University Press.

Laufer, B. (2003). Vocabulary acquisition in a second language: Do learners really acquire most vocabulary by reading? Some empirical evidence. The Canadian Modern Language Review, 59(4), 567-587. http://dx.doi.org/10.3138/cmlr.59.4.567

Laufer, B. (2005). Focus on form in second language vocabulary learning. EUROSLA Yearbook, 5(1), 223-250. http://dx.doi.org/10.1075/eurosla.5.11lau

Laufer, B., Elder, C., Hill, K., \& Congdon, P. (2004). Size and strength: Do we need both to measure vocabulary knowledge? Language Testing, 21(2), 202-226.

http://dx.doi.org/10.1191/0265532204lt277oa

Littlewood, W. (2007). Communicative and task-based language teaching in East Asian classrooms. Language Teaching, 40(3), 243-249.

http://dx.doi.org/10.1017/S0261444807004363

Long, M. H., \& Robinson, P. (1998). Focus on form: Theory, research and practice. In C. Doughty \& J. Williams (Eds.), Focus on form in classroom second language acquisition (pp. 15-41). Cambridge, England: Cambridge University Press.

Nation, I. S. P. (2006). How large a vocabulary is needed for reading and listening? The Canadian Modern Language Review, 63(1), 59-82. http://dx.doi.org/10.3138/cmlr.63.1.59

Nation, P., \& Chung, T. (2009). Teaching and testing vocabulary. In M. H. Long \& C. J. Doughty (Eds.), The handbook of language teaching (pp. 543-559). Malden, MA: Wiley-Blackwell. http://dx.doi.org/10.1002/9781444315783.ch28

Newton, J. (2001). Options for vocabulary learning through communication tasks. ELT Journal, 55(1), 30-37. http://dx.doi.org/10.1093/elt/55.1.30

Samuda, V., \& Bygate, M. (2008). Tasks in second language learning. Basingstoke, England: Palgrave Macmillan.

Saragi, T., Nation, I. S. P., \& Meister, G. F. (1978). Vocabulary learning and reading. System, 6(2), 72-128.

Schmitt, N. (2008). Review article: Instructed second language vocabulary learning. Language Teaching Research, 12(3), 329-363. http://dx.doi.org/10.1177/1362168808089921 
Sonbul, S., \& Schmitt, N. (2009). Direct teaching of vocabulary after reading: Is it worth the effort? ELT Journal, 64(3), 253-260. http://dx.doi.org/10.1093/elt/ccp059

Swan, M. (2005). Legislation by hypothesis: The case of task-based instruction. Applied Linguistics, 26(3), 376-401. http://dx.doi.org/10.1093/applin/ami013

Van den Branden, K., Bygate, M., \& Norris, J. M. (2009). Task-based language teaching: Introducing the reader. In K. Van de Branden, M. Bygate, \& J. M. Norris (Eds.), Taskbased language teaching: A reader (pp. 1-13). Amsterdam, The Netherlands: John Benjamins.

Webb, S. (2007). The effects of repetition on vocabulary knowledge. Applied Linguistics, 28(1), 46-65. http://dx.doi.org/10.1093/applin/aml048

Willis, J. (1996). A framework for task-based learning. Harlow, England: Longman.

Willis, D., \& Willis, J. (2007). Doing task-based teaching. Oxford, England: Oxford University Press. 


\section{Appendix \\ Examples of Types of Vocabulary Exercises}

The following is a summary of possible directions of vocabulary exercises classified by Folse (2004):

1. Matching

Match the words in the left column with the definitions in the right column.
A. plumber
an extending chair designed for someone to relax on
B. lounger a person who installs and fixes water piping

(Distractors are possible in either column. Pictures can be used to replace definitions.)

2. Defining

Write a good definition for the word stubborn.

3. Labelling

Write the words according to the given definitions.

$\mathrm{m}_{-}{ }_{-} \mathrm{u}_{-}{ }_{-}$a silver-white, heavily toxic metallic element which is liquid at room temperature

4. True-false

Read the statements and write true or false.

Luggage and spare tires are often kept in the trunk of a car.

5. Odd-man out

Circle the word that is different from the other three.

mutton veal carrot pork 


\section{Cloze sentences}

Fill in the blanks with the given words.

carpet, sill

She sat with one elbow resting on the The floor is covered with a beautiful of the open window. made of wool.

(Distractors can be added. Passages can be used instead of sentences.)

\section{Word forms}

Provide the verb form for the given nouns and adjectives.

anticipation >

hesitant

\section{Error identification}

One of the three underlined words is incorrect. Circle the error and write a correction above.

Because of the rain, the press conference has to be put on until tomorrow.

\section{Answering questions}

Answer questions which include the new words.

What happens to someone if he or she has asthma?

10. Original sentences

For each word, write an original sentence that shows your understanding of its meaning. communicate:

\section{Original story}

Write a story about anything, using all the given words.

complain, mistake, request, satisfied 